\title{
Dynamic pricing and periodic ordering for a stochastic inventory system with deteriorating items *
}

\author{
Yu Li ${ }^{\text {a }}$, Shuhua Zhang ${ }^{\mathrm{a}}$, Jingwen Han ${ }^{\mathrm{b}}$

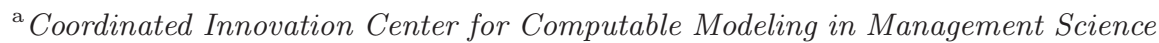 \\ Tianjin University of Finance and Economics, Tianjin 300222, China \\ ${ }^{\mathrm{b}}$ School of Science and Technology \\ Tianjin University of Finance and Economics, Tianjin 300222, China
}

\begin{abstract}
In this paper, we consider a problem of the dynamic pricing and the periodic ordering for deteriorating items with a stochastic inventory level depending on the stock-dependent demand and the selling price. In the model to be established, both shortages and remains are allowed, and the backlogging rate is variable and dependent on the waiting time for the next replenishment. Combined with the dynamic pricing, a stochastic dynamic optimization model, which maximizes the total profit, is developed. Based on the dynamic programming principle, the stochastic control model is transformed into an Hamilton-Jacobi-Bellman (HJB) equation. We show that there exists an optimal replenishment cycle length with an optimal inventory level at start of cycle. Moreover, the optimal pricing strategies are given. In addition, the finite difference scheme with the semi-smooth Newton method is proposed to solve the HJB equation numerically, and some numerical simulations are presented to illustrate the theoretical results. The sensitivity analysis of the optimal solution with respect to the major parameters is carried out and some managerial insights are proposed.
\end{abstract}

Key words: stochastic control; HJB equation; dynamic pricing; periodic ordering; deteriorating items.

\section{Introduction}

It is increasingly important to control and maintain the inventories of deteriorating items for the modern corporations. In general, the deterioration is defined as the damage, spoilage, dryness, vaporization, etc., which results in the decrease of usefulness of the original one. Usually, this characteristic can be observed in almost all food stuffs, fashionable items, electronic products, and so on.

Inventory control problems for deteriorating items have been widely studied after Ghare and Schrader (1963). First of all, the exponentially decaying inventory EOQ model is proposed. Later on, Covert and Philip (1973) formulates the model by a variable deterioration rate

\section{‡}

Email addresses: liyu@lsec.cc.ac.cn (Yu Li), szhang@tjufe.edu.cn (Shuhua Zhang), jingwenhan@126. com (Jingwen Han). with a two-parameter Weibull distribution. Soon after, Philip (1974) develops the inventory model with a three-parameter Weibull distribution rate, in which the shortage is not allowed. Furthermore, Shah (1977) extends the model established by Philip (1974) and considers the case in which the shortage is allowed. In addition, Goyal and Giri (2001) and Bakker et al. (2012) have provided a detailed review on the deteriorating inventory literature for more than a decade.

It is assumed in the traditional inventory models that the demand is constant and insensitive to either the stock level or the shortage level. However, in some situations (e.g., the retail sales), the demand rate is expected to depend on the stock level. Especially for perishable items, an increase in shelf space for an item induces more consumers to buy it. This occurs because of its visibility, popularity or variety. Conversely, low stocks of certain baked goods (e.g., donuts) might raise the perception that they are not fresh. Therefore, building up inventory often has a positive impact on the sales and the profits. Thus, the impact of product availability on stimulat- 
ing demand is discussed by Schary and Becker (1972), and the empirical evidence of the demand rate changing with the stock level changing is presented by Wolfe (1968). Later, many researchers have given considerable attentions to the situation where the demand rate is dependent on the level of the on-hand inventory. For example, Gupta and Vrat (1986) is the first paper to establish models for stock-dependent consumption rates. Also, Baker and Urban (1988) develops an economic order quantity model for a power-form inventory-leveldependent demand pattern, and Mandal and Phaujdar (1989) probes an economic production quantity model for deteriorating items with the constant production rate and linearly stock-dependent demand. Certainly, there are a lot other researches related to this area, such as Pal et al. (1993), Padmanabhan and Vrat (1995), Giri et al. (1996), Ray and Chaudhuri (1997), Datta et al. (1998), Ray et al. (1998), and so on.

It is well known that in traditional inventory models, the relationship between the sales price and the economic order quantity is not considered. In recent years, the rapid evolution of information technologies and the corresponding growth of the Internet and ecommerce make the dynamic pricing much easier and more popular, and the importance of coordinating the pricing decision with the replenishment policy when managing inventory has been recognized in practice and academic community. The basic idea is that the demands and the potential profits will be influenced by the price setting. Whitin (1955) is the first researcher to extend the basic EOQ model by considering the selling price in addition to the order quantity as the decision variable. Lilien and Kotler (1983) integrates marketing policies into inventory decisions and shows the interaction between economic order quantity and price decisions. Ladany and Sternlieb (1974) establishes a model with the sales price and the production cost dependent demand. They identify that the net profit will increase as determining an economic order quantity by considering the sales price and the demand as a function of purchase price. Rosenblatt and Lee (1985) examines a model for determining simultaneously the price and the lot size for the supplier-buyer problem by considering a scheme of quantity discounts. Polatoglu (1991) develops an inventory model for pricing and procurement decisions simultaneously. Under the condition of price-sensitive demand, the supplier's quantity discount from the perspective of reducing the supplier's operating cost and increasing the buyer's demand is considered by Weng (1995). Recently, there has been a large body of literature on the problem of coordination of replenishment strategies and pricing policies. See, for example, Federgruen and Heching (1999), Khouja (2000), Sethi and Thompson (2000), Lau and Lau (2003), Banerjee (2005), Chen and Simchi-Levi (2004, 2006), Maddah and Bish (2007), You and Hsieh (2007), Li et al. (2015), and so on.
For an inventory system exhibiting a stock-dependent demand rate, as shown in Baker and Urban (1988), its objective is to maximize the profit rather than to minimize the costs. Moreover, as stated in Urban (1992), whenever the demand rate is influenced by the displayed stock level, it is more profitable to keep a higher inventory level, hoping to generate more demands, even if it turns up in the non-zero ending inventory. Otherwise, in the inventory system that possesses a stock-dependent demand rate, a higher level of inventory causes not only higher inventory and deterioration costs but also higher purchase price due to the increase in demand. Recently, some researchers, such as Teng et al. (2011), Yang et al. (2011), Soni (2013), advocate these viewpoints and develop their models under different conditions.

Furthermore, when the shortages occur, some customers are willing to wait for the backorders, and others would turn to buy from other sellers. Many researchers, such as Park (1982), Hollter and Mak (1983), Wee (1995), consider the constant partial backlogging rates during the shortage period in their inventory models. In some inventory systems, such as fashionable commodities, the length of the waiting time for the next replenishment would determine whether the backlogging will be accepted or not. Therefore, the backlogging rate is variable and dependent on the waiting time for the next replenishment. In fact, Chang and Dye (1999) investigates an EOQ model allowing shortage and partial backlogging, in which it is assumed that the backlogging rate is variable and dependent on the length of the waiting time for the next replenishment. Recently, many researches have modified inventory policies by considering the "timeproportional partial backlogging rate", such as Abad (2000), Papachristos and Skouri (2000), Chang and Dye (2001), Wang (2002), Papachristos and Skouri (2003), etc.

For fitting in with realistic circumstances, in this paper we present a continuous time stochastic inventory model with deteriorating products in the setting of dynamic pricing and periodic ordering policy. The deterioration rate of inventory level is used to describe the deteriorating items, and the demand rate is supposed to take a linear function of the selling price and stock. Also, in this model both the shortages and the remains are allowed, and the backlogging rate is variable and dependent on the waiting time for the next replenishment. By applying the stochastic optimal control method, it turns out that the problem of finding the optimal pricing is converted to the problem of solving an HJB equation. The proposed model can be used to describe quantitatively different types of inventory systems, like the electronic manufacturing system and the clothing manufacturing industry, and so on. What is more, some theoretical results of the existence and uniqueness of the optimal solution are shown. We show that there exists an optimal replenishment cycle length with an optimal inventory level at start of cycle. Moreover, the optimal pricing strate- 
gies will be given. Finally, some numerical examples are presented to demonstrate the developed model and the procedure to get the solution. The sensitivity analysis of the optimal solution with respect to the major parameters is carried out, and some managerial insights are proposed.

The rest of the paper is organized as follows. In the next section, the notations and assumptions related to this study are presented. In Section 3, we formulate the model by considering the possible costs and revenues. In Section 4, it is proved that the optimal periodic ordering policy exists uniquely. Moreover, the optimality conditions are derived to find optimal selling price. In Section 5, it is shown that the solution of the proposed HJB equation cannot be got just from the ordinary differential equations (ODEs). In Sections 6 and 7, several numerical examples and the sensitivity analysis are presented to illustrate the obtained theoretical results. Finally, concluding remarks are presented in Section 8.

\section{Notations and Assumptions}

In this section, we prescribe some notations and assumptions to be used in the following discussion. First of all, we need the following notations:

- $T$ : the duration of a replenishment cycle, such as one week, one month, one quarter. That means the retailer adopts a periodic replenishment policy.

- $I(t)$ : the inventory level at time $t \in[0, T]$.

- $p(t)$ : the selling price per unit at time $t \in[0, T]$, where $p(t) \geq 0$.

- $\alpha$ : the sensitivity of the demand with respect to the selling price, where $\alpha<0$.

- $\beta$ : the sensitivity of the demand with respect to the inventory level.

- $d W$ : the increment of standard Brownian process.

- $b$ : the fixed term of demand rate determined by the market size.

- $C$ : the ordering cost per replenishment cycle, which is independent of the order quantity.

- $c$ : the purchase price per unit.

- $h$ : the inventory holding cost per unit.

- $\gamma$ : punishment coefficient when stock-out, where $\gamma>$ 0 .

- $s_{v}$ : the salvage price per unit at the end of the replenishment cycle. We assume without loss of generality that $s_{v} \leq c$.

- $U$ : the maximum inventory level.

Also, we need the following assumptions:

- The inventory system involves a single deteriorating item.

- The selling price changes over time and needs to be determined by the retailer himself in order to maximize his expected total profit.
- $W_{s}^{1}$ and $W_{s}^{2}$ are independent standard Brownian processes.

- The cumulative demand $D(t)$ is a stochastic process given by

$$
d D(s)=(b+\alpha p(s)+\beta I(s)) d s+\sigma_{2} d W_{s}^{2},
$$

which is dependent on the selling price $p(s)$ and the inventory level $I(s)$, where $\sigma_{2}>0$. Moreover, we always assume that $b+\alpha c>0$ holds, otherwise there is no market for this kind of items.

- The inventory level is influenced by both the demand and the deterioration rate with uncertainty. The process of deterioration is described by geometric Brownian motion, which means that there is a random deterioration rate with a Gaussian white noise.

- The ending inventory level is not restricted, i.e., the shortages and the remains are both allowed.

- There is no repair or replacement of the deteriorated inventory (i.e., the salvage value of a deteriorating item is zero).

- Replenishment rate is infinite and the lead time is zero.

- The time value of money is ignored.

- In real life, the most retail outlets have a limited shelf space. Hence, we impose a maximum inventory level $U$ in the model to reflect this fact. That is, $I(t) \leq U$ for all $t \in[0, T]$.

- In U.S., many sushi stores dump daily the remaining goods with big discounts at an hour before closing. Likewise, numerous department stores reduce price significantly to sell out out-of-season dresses during weekends. Hence, it is reasonable to assume that if the ending inventory level is not zero (i.e., $I(T)>0$ ), these units are sold with salvage price under the purchase price at the end of cycle.

\section{The Model Formulation}

Considering the uncertainty of the demand and the deteriorating rate which may be influenced by the social or economical environments, from the above notations and assumptions, the status of inventory at any instant $t \in[0, T]$ is governed by the following stochastic differential equation: for $s>t$,

$$
\left\{\begin{aligned}
d I(s)= & -\left(\theta I(s) d s+\sigma_{1} I(s) d W_{s}^{1}\right)-d D(s) \\
= & (-\theta I(s)-[b+\alpha p(s)+\beta I(s)]) d s \\
& +\sqrt{\sigma_{1}^{2} I^{2}(s)+\sigma_{2}^{2}} d W_{s}, \\
I(t)= & x,
\end{aligned}\right.
$$

where $x$ denotes the inventory level at time $t$. During the time interval $[s, s+d s)$, the change of the inventory level $d I(s)$ is divided into two parts. The first part is $\theta I(s) d s+\sigma_{1} I(s) d W_{s}^{1}$, which represents the random 
quantity of deteriorative item. The second part is $d D(s)$, which represents the random quantity of sold item. After the current time $t$, the moment of the item sold out is denoted by $\tau$ when the inventory level is zero before the next replenishment, i.e., $\tau<T$, otherwise $\tau=T$, which means that there is the remaining stock. Thus, it can be described as:

$$
\tau=\inf \{s>t:(s, I(s)) \notin(0, T) \times(0, U)\} .
$$

Now we need to present all the relevant costs and the sales revenues per replenishment cycle at the initial time $t$, which results from the following components:

- The profit on sale is given by

$$
\begin{aligned}
& \int_{t}^{\tau} p(s) d D(s)+s_{v} I(\tau)-c x \\
= & \int_{t}^{\tau} p(s)[b+\alpha p(s)+\beta I(s)] d s+s_{v} I(\tau)-c x \\
& +\int_{t}^{\tau} p(s) \sigma_{2} d W_{s}^{1} .
\end{aligned}
$$

If the products are out of stock, $\tau<T$ and $I(\tau)=0$. Otherwise, there are surplus goods at the end of cycle, i.e., $\tau=T$ and $I(\tau)>0$. Then, the salvage revenue of the remaining inventory is $s_{v} I(\tau)$.

- The inventory holding cost is presented by

$$
\int_{t}^{\tau} h I(s) d s
$$

- During the shortage period, the profit is represented by

$$
\begin{aligned}
& \int_{\tau}^{T}[p(s)-c] e^{-\gamma(T-s)} d D(s) \\
= & \int_{\tau}^{T}[p(s)-c][b+\alpha p(s)] e^{-\gamma(T-s)} d s \\
& +\int_{\tau}^{T}[p(s)-c] e^{-\gamma(T-s)} \sigma_{2} d W_{s}^{2} .
\end{aligned}
$$

This means that when $I(s)=0$, the retailer will not lose his customers completely who are not satisfied with the retailer. In addition, when $I(s)=0$, the backlogging rate depends on the delay in days between the confirmation of the customer order and the delivery of the finished products.

- The ordering cost per cycle is represented by $C$.

According to the above components, the retailer should find an optimal selling price which maximizes the expected value of the flow of instantaneous net profit. Therefore, the above problem can be described as a stochastic optimal control problem without the ordering cost:

$$
\begin{aligned}
& V(t, I(t) ; T)=\sup _{p} E\left\{\int_{t}^{\tau} p(s)[b+\alpha p(s)+\beta I(s)] d s\right. \\
& \quad-\int_{t}^{\tau} h I(s) d s+s_{v} I(\tau) \\
& \left.\quad+\int_{\tau}^{T}[p(s)-c][b+\alpha p(s)] e^{-\gamma(T-s)} d s\right\}-c x
\end{aligned}
$$

s.t. (1) holds and $0 \leq p(s) \leq \frac{b+\beta I(s)}{-\alpha}$ for all $s \in[t, T]$.

In the above formula, $t \in[0, T]$ and the control policy $p(s)$ is the selling price, whose upper bound comes from the fact that the demand rate should remain nonnegative. During the period of shortage, the retailer can make orders, but cannot make delivery at once. Since the delivery is postponed, the demand rate is multiplied by the punishment factor $e^{-\gamma(T-t)}$, which depends on the delay time length $T-t$. Actually, facing the stock-out situation, the retailer should make the optimal selling price in order to maximize his profit during this period, which means that the optimal selling price is

$$
\bar{p}=\frac{b-\alpha c}{-2 \alpha}
$$

and the profit is

$\int_{\tau}^{T}(\bar{p}-c)(b+\alpha \bar{p}) e^{-\gamma(T-s)} d s=\frac{(b+\alpha c)^{2}}{-4 \alpha} \frac{1-e^{-\gamma(T-\tau)}}{\gamma}$

When $t=0$, the replenishment cycle starts at time 0 and ends at time $T$, during which there is no other replenishment. After the determination of the optimal pricing strategy $p^{*}$, we get the value function $V(0, \cdot ; T)$ at time 0 with respect to the inventory level, from which we can then derive the optimal inventory level at time 0. One of the advantages of the model is that we can extend $t=0$ to an arbitrary $t \in[0, T]$, which means if the replenishment happens at arbitrary time $t$ during the replenishment cycle and the retailer will replenish again over the period of $[t, T]$. Also, the model can also determine the optimal pricing strategy from now on.

When the stock is full, i.e., the retailer has the maximum inventory level $U$, we assume that the marginal total profit of the inventory level is zero. That is,

$$
\frac{\partial V}{\partial x}(t, U ; T)=0 .
$$


Consequently, the maximum total profit per unit time with given replenishment cycle $T$ is

$$
\begin{aligned}
& \Pi\left(T, x^{*}(0 ; T)\right)=\sup _{x} \Pi(T, x) \\
= & \frac{1}{T}\left(V\left(0, x^{*}(0 ; T) ; T\right)-C\right),
\end{aligned}
$$

where

$$
\Pi(T, x)=\frac{1}{T}(V(0, x ; T)-C),
$$

and $x^{*}(0 ; T)$ is the optimal inventory level at the start of cycle, the length of which is $T$. Moreover, the optimal total profit per unit time is

$$
\begin{aligned}
\Pi^{*} & =\sup _{T} \Pi\left(T, x^{*}(0 ; T)\right) \\
& =\frac{1}{T^{*}}\left(V\left(0, x^{*}\left(0 ; T^{*}\right) ; T^{*}\right)-C\right),
\end{aligned}
$$

where $T^{*}$ is the optimal replenishment cycle length from $t=0$.

\section{Theoretical Results}

In this section, the value function $V$ defined in (3) will be solved by an HJB equation according to the dynamic programming principle. Also, the optimal $x^{*}$ and $T^{*}$ in (4) and (6) will be determined. In addition, some theoretical results will be given.

For each choice of the function $p$, the solution $I$ defined by (1) is an Itô diffusion with the generator $\mathcal{A}^{p}$ given by, for $\phi \in C_{0}^{2}(\mathbb{R} \times \mathbb{R})$,

$$
\left(\mathcal{A}^{p} \phi\right)(t, x)=\frac{\partial \phi}{\partial t}(t, x)-\left(\mathcal{L}^{p} \phi\right)(t, x)
$$

where

$$
\begin{aligned}
\left(\mathcal{L}^{p} \phi\right)(t, x)= & -[-\theta x-(b+\alpha p+\beta x)] \frac{\partial \phi}{\partial x} \\
& -\frac{1}{2}\left(\sigma_{1}^{2} x^{2}+\sigma_{2}^{2}\right) \frac{\partial^{2} \phi}{\partial x^{2}},
\end{aligned}
$$

for all $p \in \Lambda(x)=\left(0, \frac{b+\beta x}{-\alpha}\right)$ and $\phi \in C_{0}^{2}(\mathbb{R} \times \mathbb{R})$. Let $f: \mathbb{R} \times \mathbb{R} \times \Lambda \mapsto \mathbb{R}$ and $g: \mathbb{R} \times \mathbb{R} \mapsto \mathbb{R}$ be given continuous functions called "profit rate" function and "bequest" function, respectively, which are defined as follows:

$$
\begin{aligned}
f(t, x, p) & =(p-c)(b+\alpha p+\beta x)-c \theta x-h x, \\
g(t, x) & =\frac{(b+\alpha c)^{2}}{-4 \alpha} \frac{1-e^{-\gamma(T-t)}}{\gamma}+\left(s_{v}-c\right) x .
\end{aligned}
$$

Then, the HJB equation is proposed as follows: for all $(t, x) \in G=(0, T) \times(0, U)$,

$$
\frac{\partial u}{\partial t}(t, x)+\sup _{p \in \Lambda(x)}\left\{-\left(\mathcal{L}^{p} u\right)(t, x)+f(t, x, p)\right\}=0
$$

with the boundary condition $u=g$ on $\{T\} \times[0, U] \cup$ $(0, T) \times\{0\}$ and the artificial boundary condition $\frac{\partial u}{\partial x}(t, U)=0$ for all $t \in[0, T]$.

The following lemma summarizes several results about the solution $u$ of the HJB equation (11) and the control variable $p$ presented in Theorems 11.2.1 and 11.2.2 in Øksendal (2003) and Theorems IV.4.1 and IV.4.2 in Fleming and Soner (2006).

Lemma 1 The HJB equation (11) has a unique solution $u \in C^{1,2}(G) \cap C(\bar{G})$ and there exists a function $p^{*}(t, x)$ such that

$$
p^{*}(t, x)=\arg \sup _{p \in \Lambda}\left\{-\left(\mathcal{L}^{p} u\right)(t, x)+f(t, x, p)\right\},
$$

which is an optimal Markov control policy. Moreover, the solution of the HJB equation (11) is the value function of the stochastic optimal control problem (3).

In the next theorem, the key factors of the model described in last section, such as $t^{*}, x^{*}(t), p^{*}(t, x)$ and $\Pi^{*}$, are rebuilt using the solution of HJB equation. Although its proof is simple seemingly, this theorem emphasizes that the coefficients are independent of the current time, which is important for the theorematic analysis and numerical simulation for our model.

Theorem 2 For the solution $u$ of the HJB equation (11), we have

$$
u(t, x)=V(0, x ; T-t), \text { for all }(t, x) \in[0, T] \times[0, U] .
$$

In addition, for the given $t \in[0, T]$, there exists the optimal $x^{*}(t) \in[0, U]$ such that

$$
\sup _{x \in[0, U]} u(t, x)=u\left(t, x^{*}(t)\right)
$$

Moreover, there exists $t^{*} \in[0, T]$ such that

$$
\begin{aligned}
\Pi^{*} & =\sup _{t \in[0, T]} \frac{1}{T-t}\left[u\left(t, x^{*}(t)\right)-C\right] \\
& =\frac{1}{T-t^{*}}\left[u\left(t, x^{*}\left(t^{*}\right)\right)-C\right],
\end{aligned}
$$

where the optimal replenishment cycle is $T-t^{*}$ and the optimal initial inventory level is $x^{*}\left(t^{*}\right)$ with the optimal price $p^{*}\left(t^{*}, x^{*}\left(t^{*}\right)\right)$ at start of cycle. 
PROOF. Set $\tilde{\tau}=\tau-t, \tilde{s}=s-t$ and $\tilde{I}^{0, x}(\tilde{s})=I^{t, x}(\tilde{s}+$ $t), \tilde{p}(\tilde{s})=p(\tilde{s}+t)$. Then, it follows from substituting these into (1) and (3) that

$$
\begin{aligned}
d I(\tilde{s}+t)= & (-\theta I(\tilde{s}+t)-[b+\alpha p(\tilde{s}+t)+\beta I(\tilde{s}+t)]) d \tilde{s} \\
& +\sqrt{\sigma_{1}^{2} I(\tilde{s}+t)^{2}+\sigma_{2}^{2}} d W
\end{aligned}
$$

with $I(t)=x$. That is,

$$
\begin{aligned}
d \tilde{I}(\tilde{s})= & (-\theta \tilde{I}(\tilde{s})-[b+\alpha \tilde{p}(\tilde{s})+\beta \tilde{I}(\tilde{s})]) d \tilde{s} \\
& +\sqrt{\sigma_{1}^{2} \tilde{I}(\tilde{s})^{2}+\sigma_{2}^{2}} d W
\end{aligned}
$$

with $\tilde{I}(0)=x$, and

$$
\begin{aligned}
& V(t, x ; T)=\sup _{p} E\left\{\int_{t}^{\tau}[p(s)(b+\alpha p(s)+\beta I(s))\right. \\
& \quad-h I(s)] d s+s_{v} I(\tau) \\
& \left.\quad+\int_{\tau}^{T}(\bar{p}-c)(b+\alpha \bar{p}) e^{-\gamma(T-s)} d s\right\}-c x \\
& =\sup _{p} E\left\{\int_{0}^{\tau-t}[p(\tilde{s}+t)(b+\alpha p(\tilde{s}+t)+\beta I(\tilde{s}+t))\right. \\
& \quad-h I(\tilde{s}+t)] d \tilde{s}+s_{v} I(\tau-t+t) \\
& \left.\quad+\int_{\tau-t}^{T-t}(\bar{p}-c)(b+\alpha \bar{p}) e^{-\gamma(T-\tilde{s}-t)} d \tilde{s}\right\}-c x \\
& =\sup _{\tilde{p}} E\left\{\int_{0}^{\tau}[\tilde{p}(\tilde{s})(b+\alpha \tilde{p}(\tilde{s})+\beta \tilde{I}(\tilde{s}))-h \tilde{I}(\tilde{s})] d \tilde{s}\right. \\
& \left.\quad+s_{v} \tilde{I}(\tilde{\tau})+\int_{\tilde{\tau}}^{T-t}(\bar{p}-c)(b+\alpha \bar{p}) e^{-\gamma((T-t)-\tilde{s})} d \tilde{s}\right\} \\
& \quad-c x \\
& =V(0, x ; T-t) .
\end{aligned}
$$

Therefore, according to Lemma 1,

$$
u(t, x)=V(t, x ; T)=V(0, x ; T-t),
$$

and the unique solution $u$ of the HJB equation (11) belongs to the function space $C^{1,2}(G) \cap C(\bar{G})$. Additionally, according to the extreme value theorem the equations (13) and (14) hold.

Remark 3 If the coefficients are dependent on the time, we can not get the above theorem. In that case, we should compute the value function for each different length of cycle throughout the numerical algorithm.

Theorem 4 For the given $(t, x) \in[0, T) \times[0, U]$, if $\frac{\partial u}{\partial x}(t, x)$ belongs to the interval $\left(\frac{b-\alpha c+\beta x}{\alpha}, \frac{b+\alpha c+\beta x}{-\alpha}\right)$, $p^{*}(t, x)$ defined by (12) satisfies

$$
p^{*}(t, x)=\frac{\beta x}{-2 \alpha}+\frac{1}{2} \frac{\partial u}{\partial x}(t, x)+\frac{b-\alpha c}{-2 \alpha} .
$$

Moreover, if $\frac{\partial u}{\partial x}(t, x)>\frac{\beta x}{\alpha}, p^{*}(t, x)>c$.

PROOF. According to the definition of $\mathcal{L}^{p}$ in $(8)$ and $f$ in $(9)$, we get

$$
\begin{aligned}
& -\left(\mathcal{L}^{p} u\right)(t, x)+f(t, x, p) \\
= & \alpha p^{2}+\left[b-\alpha c+\beta x-\alpha \frac{\partial u}{\partial x}(t, x)\right] p \\
& +(-\theta-b-\beta x) \frac{\partial u}{\partial x}(t, x)+\frac{1}{2} \sigma^{2} \frac{\partial^{2} u}{\partial x^{2}}(t, x) \\
& -c(b+\beta x)-c \theta x-h x .
\end{aligned}
$$

It follows from $b-\alpha c+\beta x-\alpha \frac{\partial u}{\partial x}(t, x)>0$ and (12) that

$$
p^{*}(t, x)=\frac{\beta x}{-2 \alpha}+\frac{1}{2} \frac{\partial u}{\partial x}(t, x)+\frac{b-\alpha c}{-2 \alpha} .
$$

Moreover,

$$
p^{*}(t, x)-c=\frac{b+\alpha c}{-2 \alpha}+\frac{1}{2}\left[\frac{\partial u}{\partial x}(t, x)-\frac{\beta x}{\alpha}\right] .
$$

So, when $\frac{\partial u}{\partial x}(t, x)>\frac{\beta x}{\alpha}$, we, together with $b+\alpha c>0$, have that $p^{*}(t, x)>c$.

The value function is not a linear or quadratic function, so $p^{*}$ defined by (15) is not dependent on $x$ linearly as usual. The numerical results and the closed form have shown this result. Under the optimal condition, some properties are shown.

Corollary 5 For the given $t \in[0, T)$, if $x^{*}(t)$ defined by (13) belongs to the open interval $(0, U)$, there holds

$$
p^{*}\left(t, x^{*}(t)\right)=\frac{\beta x^{*}(t)}{-2 \alpha}+\frac{b-\alpha c}{-2 \alpha}>c
$$

Moreover, when $t^{*}$ defined by (14) belongs to the open interval $(0, T)$,

$$
\begin{aligned}
\Pi^{*}= & \frac{1}{-4 \alpha}\left[b+\alpha c+\beta x^{*}\left(t^{*}\right)\right]^{2}-(c \theta+h) x^{*}\left(t^{*}\right) \\
& +\frac{1}{2}\left(\sigma_{1}^{2} x^{*}\left(t^{*}\right)^{2}+\sigma_{2}^{2}\right) \frac{\partial^{2} u}{\partial x^{2}}\left(t^{*}, x^{*}\left(t^{*}\right)\right) .
\end{aligned}
$$


PROOF. By virtue of Lemma 1, we know the solution of (11) $u \in C^{1,2}(G) \cap C(\bar{G})$. Furthermore, from the profit maximization principle, $\frac{\partial u}{\partial x}\left(t, x^{*}(t)\right)=0$ and $\frac{\partial^{2} u}{\partial x^{2}}\left(t, x^{*}(t)\right)<0$ hold. From Theorem 4,

$$
p^{*}\left(t, x^{*}(t)\right)=\frac{\beta x^{*}(t)}{-2 \alpha}+\frac{1}{2} \frac{\partial u}{\partial x}\left(t, x^{*}(t)\right)+\frac{b-\alpha c}{-2 \alpha},
$$

which is (16).

Since $\frac{\partial u}{\partial x}\left(t, x^{*}(t)\right)=0$, we obtain

$$
\begin{aligned}
& \frac{d}{d t} \Pi\left(T-t, x^{*}(t)\right) \\
= & \frac{-1}{(T-t)^{2}}\left[\frac{\partial u}{\partial t}\left(t, x^{*}(t)\right)(T-t)+u\left(t, x^{*}(t)\right)-C\right] .
\end{aligned}
$$

Substituting $x^{*}$ and $p^{*}\left(t, x^{*}\right)$ into the HJB equation (11) yields that

$$
\begin{aligned}
& \frac{\partial u}{\partial t}\left(t, x^{*}(t)\right)+\frac{1}{2}\left(\sigma_{1}^{2} x^{*}(t)^{2}+\sigma_{2}^{2}\right) \frac{\partial^{2} u}{\partial x^{2}}\left(t, x^{*}(t)\right) \\
& +\frac{1}{-4 \alpha}\left[b+\alpha c+\beta x^{*}(t)\right]^{2}-(c \theta+h) x^{*}(t)=0 .
\end{aligned}
$$

According to $\frac{d}{d t} \Pi\left(T-t^{*}, x^{*}\left(t^{*}\right)\right)=0$ due to the profit maximization principle, we gain

$$
\begin{aligned}
\Pi^{*}= & \Pi\left(T-t^{*}, x^{*}\left(t^{*}\right)\right)=\frac{u\left(t^{*}, x^{*}\left(t^{*}\right)\right)-C}{T-t^{*}} \\
= & -\frac{\partial u}{\partial t}\left(t^{*}, x^{*}\left(t^{*}\right)\right) \\
= & \frac{1}{-4 \alpha}\left[b+\alpha c+\beta x^{*}\left(t^{*}\right)\right]^{2}-(c \theta+h) x^{*}\left(t^{*}\right) \\
& +\frac{1}{2}\left(\sigma_{1}^{2} x^{*}\left(t^{*}\right)^{2}+\sigma_{2}^{2}\right) \frac{\partial^{2} u}{\partial x^{2}}\left(t^{*}, x^{*}\left(t^{*}\right)\right),
\end{aligned}
$$

which is the desired result (17) and the proof is complete.

For the given $t \in[0, T)$, according to the definition of $x^{*}(t)$ in $(13)$, if $x^{*}(t) \in(0, U)$, it is the root of equation $\frac{\partial u}{\partial x}(t, x)=0$. This means that $x^{*}(t)$ is the inventory level when the marginal expected total profits $V-C$ of the inventory level is zero. At this point, the expected total profits for the fixed replenishment cycle length has reached the maximum value. In addition, from equation (16) we know that the relationship between the optimal selling price and the optimal inventory level is linear.

Remark 6 The equation (17) implies when the volatility of inventory level is small enough, there is a quadratic function relationship between the optimal inventory level and the expected total profits per unit time under the optimal replenishment cycle. The relationship between $\Pi^{*}$ and $x^{*}\left(t^{*}\right)$ is very special, which holds under the optimal cycle length of replenishment $T-t^{*}$ and the optimal inventory level $x^{*}\left(t^{*}\right)$ at start of cycle. This equation is verified in Section $\%$.

\section{The Closed Form}

In this section, we want to explain that the numerical method is necessary for the analysis of the inventory problem with deterioration for our model, which can not be handled by ODEs. Even if in the special case, the exact solution of HJB equation is not a simple linear or quadratic function.

Without considering the boundary condition, we assume that the value function $u$ has a quadratic polynomial form

$$
u(t, x)=l(t) x^{2}+n(t) x+m(t)
$$

and the conditions of Theorem 4 hold, i.e., there is no constraint on the control variable $p$. Then, substituting the above quadratic polynomial form into the HJB equation (11), we obtain the following ordinary differential equations (ODEs):

$$
\frac{d}{d t}\left(\begin{array}{l}
l \\
n \\
m
\end{array}\right)=\left(\begin{array}{c}
\alpha l^{2}+\left(2 \theta+\beta-\sigma_{1}^{2}\right) l+\frac{\beta^{2}}{4 \alpha} \\
\left(\frac{\beta}{2}+\alpha l+\theta\right) n+(b+\alpha c)\left(l+\frac{\beta}{2 \alpha}\right)+c \theta+h \\
\frac{\alpha}{4}\left(n+\frac{b+\alpha c}{\alpha}\right)^{2}-\sigma_{2}^{2} l
\end{array}\right)
$$

According to the final condition $u(T, x)=\left(s_{v}-c\right) x$, we have that $l(T)=0, n(T)=s_{v}-c$, and $m(T)=0$. Just because of the boundary condition of the HJB equation (11)

$$
u(t, 0)=\frac{(b+\alpha c)^{2}}{-4 \alpha} \frac{1-e^{-\gamma(T-t)}}{\gamma},
$$

we can not get the exact solution $u$ of the HJB equation just from the system of ODEs (18).

Let us consider a non-real case in which $\theta=\beta=h=$ $\sigma_{1}=\sigma_{2}=0$ and $\gamma \rightarrow+\infty$. Then, when the inventory level is zero, the retailer will lose all consumers. However, the retailer should raise the selling price to $\frac{b}{-\alpha}$ in order to reduce the demand rate when the inventory level is almost zero. In other words, the retailer can avoid shortage cost as long as the inventory level is greater than zero. So, based on (15) we guess

$$
\lim _{x \rightarrow 0^{+}} \frac{\partial u}{\partial x}(t, x)=\frac{b+\alpha c}{-\alpha},
$$


and

$$
\lim _{x \rightarrow 0^{+}} u(t, x)=0 .
$$

Then, we assume that from $t$ to $T$ the inventory level decreases from $x$ to 0 , i.e.,

$$
x=(b+\alpha p)(T-t),
$$

i.e.,

$$
p=\frac{x}{\alpha(T-t)}+\frac{b}{-\alpha} .
$$

Hence, the total profit value is

$$
(p-c)(b+\alpha p)(T-t)=\frac{x^{2}}{\alpha(T-t)}+\frac{b+\alpha c}{-\alpha} x .
$$

Substituting

$$
l=\frac{1}{\alpha(T-t)} \text { and } n=\frac{b+\alpha c}{-\alpha}
$$

into (18), we get $m=0$ satisfying $m(T)=0$, i.e.,

$$
u(t, x)=\frac{x^{2}}{\alpha(T-t)}+\frac{b+\alpha c}{-\alpha} x .
$$

However, when the inventory level is large enough, the total profit value will decrease as the inventory level increases because of the loss of selling at a deep discount before the next replenishment cycle, i.e.,

$$
\lim _{x \rightarrow+\infty} \frac{\partial u}{\partial x}(t, x)=s_{v}-c .
$$

According to the continuity and smoothness of $u$ stated in Lemma 1, we construct the solution $u(t, x)$ as follows:

$$
\begin{cases}\frac{1}{\alpha(T-t)} x^{2}+\frac{b+\alpha c}{-\alpha} x, & x \in\left(0, \frac{b+\alpha s_{v}}{2}(T-t)\right), \\ \left(s_{v}-c\right) x+\frac{\left(b+\alpha s_{v}\right)^{2}}{-4 \alpha}(T-t), & x \in\left[\frac{b+\alpha s_{v}}{2}(T-t), U\right) .\end{cases}
$$

It is easy to check that (19) agrees with the HJB equation (11). Then, the optimal selling price is as follows:

$p^{*}(t, x)= \begin{cases}\frac{x}{\alpha(T-t)}+\frac{b}{-\alpha}, & x \in\left(0, \frac{b+\alpha s_{v}}{2}(T-t)\right), \\ \frac{b-\alpha s_{v}}{-2 \alpha}, & x \in\left[\frac{b+\alpha s_{v}}{2}(T-t), U\right) .\end{cases}$

From (19), (20) and $c \geq s_{v}$, we can get

$$
\begin{aligned}
& x^{*}(t)=\frac{b+\alpha c}{2}(T-t), p^{*}\left(t, x^{*}(t)\right)=\frac{b-\alpha c}{-2 \alpha}, \\
& u\left(t, x^{*}(t)\right)=\frac{(b+\alpha c)^{2}}{-4 \alpha}(T-t)
\end{aligned}
$$

and

$$
\begin{aligned}
& t^{*}=0, x^{*}\left(t^{*}\right)=\frac{b+\alpha c}{2} T, p^{*}\left(t, x^{*}\left(t^{*}\right)\right)=\frac{b-\alpha c}{-2 \alpha}, \\
& u\left(t^{*}, x^{*}\left(t^{*}\right)\right)=\frac{(b+\alpha c)^{2}}{-4 \alpha} T .
\end{aligned}
$$

Then, we have

$$
\Pi^{*}=\frac{(b+\alpha c)^{2}}{-4 \alpha}-\frac{C}{T}
$$

In fact, when there is no holding cost, no item deteriorated, no shortages and no uncertainty, the longer the length of replenishment cycle is, the higher the total profit value per unit time is.

Remark 7 For the general case, we cannot give the exact solution of the HJB equation (11) analytically. It should be a smooth connection of many quadratic functions. In the next section, we will propose a numerical scheme to solve the HJB equation (11) directly.

\section{Numerical Simulations}

In this section, the finite difference scheme with the semismooth Newton method is proposed to solve the HJB equation (11) numerically. Also, some numerical examples are provided.

Let the set $\left\{t_{k}=k \Delta t\right\}_{k=0}^{K}$ be an equipartition of $[0, T]$ with the interval length $\Delta t$ and the set $\left\{x_{i}=i \Delta x\right\}_{i=0}^{N+1}$ be an equipartition of $[0, U]$ with the interval length $\Delta x$. The detail of numerical scheme is presented in Appendix A, and the following convergence results are given in Barles and Souganidis (1991), Barles and Jakobsen (2007) and Corollary 2.2.3, Theorem 2.3.4 and Theorem 6.3.3. in Smears (2014).

Lemma 8 If $\Delta t$ is small enough, the discrete HJB equations (A.1) have a unique solution. Moreover, for every initial choice $y_{1}$, the sequence $\left\{y_{m}\right\}$ defined by Algorithm 1 converges to a solution of (A.1) superlinearly.

Lemma 9 When $\Delta t$ and $\Delta x$ tend to zero, the solution of the discrete HJB equations (A.1) uniformly tends to the unique solution of the HJB equation (11).

First, we consider the case given in last section, in which the approximate solutions computed by the above numerical scheme are consistent with the exact solutions (19) and (20).

Example 10 Consider the inventory system with the following parameters:

$$
\alpha=-2.0, b=100.0, \beta=0.0, C=80.0, c=30.0,
$$




$$
\begin{aligned}
& h=0.0, s_{v}=20, \sigma_{1}=0.0, \sigma_{2}=0.0, \theta=0.0, \\
& \gamma=10^{8}, U=200, N=K=5000 .
\end{aligned}
$$

The value function $V$ and the total profit per unit time are obtained with respect to the inventory level at the start of cycle about the different values of $T=0.75,1.50,2.25,3.00$ as shown in Figure 1. The optimal selling price with respect to the inventory level at the start of cycle and the connection between $x^{*}(t)$ and $p^{*}\left(t, x^{*}(t)\right)$ are shown in Figure 2. From Figure 1, it can be observed that the optimal replenishment cycle is 3.0 and the optimal inventory level is 60 nearly with the optimal selling price 40 almost.

Moreover, the numerical solution of $u$ is in accordance with the theory analysis from (19):

$$
u(t, x)= \begin{cases}\frac{1}{-2(T-t)} x^{2}+20 x, & x \in(0,30(T-t)), \\ -10 x+450(T-t), & x \in[30(T-t), 200) .\end{cases}
$$

In Figure 2, the optimal selling price is presented in the L-shape as increasing the inventory level at the start of cycle, which verifies the theoretical result (20):

$$
p^{*}(t, x)= \begin{cases}\frac{x}{-2(T-t)}+50, & x \in(0,30(T-t)), \\ 35, & x \in[30(T-t), 200) .\end{cases}
$$

In addition, for given $T$, the optimal selling price is constant, which verifies the theoretical result (16):

$$
p^{*}\left(t, x^{*}(t)\right)=\frac{\beta x^{*}(t)}{-2 \alpha}+\frac{b-\alpha c}{-2 \alpha}=40 .
$$
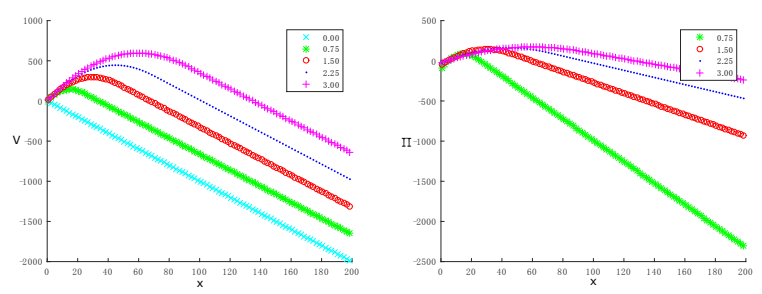

Fig. 1. $V(0, x ; T)$ and $\Pi(T, x)$ about the different values of $T$.

In the second example, we consider a general case, in which the optimal replenishment and the pricing policy are shown numerically. Moreover, one sample path of stochastic process $I$ defined by (1) is simulated according to the discrete control variable computed by the proposed numerical scheme.

Example 11 Consider the inventory system with the following parameters:

$$
\alpha=-2.0, b=100.0, \beta=0.20, C=80.0, c=30.0,
$$
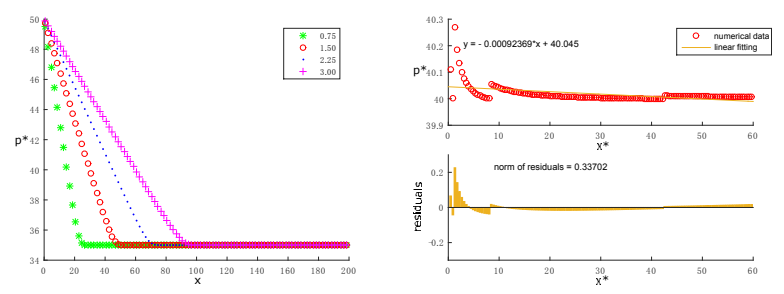

Fig. 2. $p^{*}(0, x)$ about the different values of $T$ and $p^{*}\left(t, x^{*}(t)\right)$.

$$
\begin{aligned}
& h=5.0, s_{v}=20, \sigma_{1}=0.01, \sigma_{2}=2.01, \theta=0.05 \\
& \gamma=2.0, U=200, N=K=5000 .
\end{aligned}
$$

In this example, the maximum inventory level $U$ is equal to 200, which is large enough. This means that the retailer can make decision without considering the limited shelf space.

The value function $V$ and the total profit per unit time are obtained with respect to the inventory level at the start of cycle about the different values of $T=0.75,1.50,2.25,3.00$ as shown in Figure 3. The optimal selling price with respect to the inventory level at the start of cycle and the connection between $x^{*}(t)$ and $p^{*}\left(t, x^{*}(t)\right)$ are shown in Figure 4 .

In Figure 4, the optimal selling price is presented in the $V$-shape as increasing the inventory level at the start of cycle. For the given replenishment cycle length, the large shortage cost occurs when the inventory level at the start of cycle is too small, so the optimal selling price is high in order to decrease the demand rate and reduce the shortage time. The large cost of deterioration and the selling at loss at the end of cycle come up when the inventory level at the start of cycle is too high, so the optimal selling price is also high, which results in increasing demand rate with large stocks.

In addition, for a given $T$, there is a linear relationship between the optimal selling price and the optimal inventory level, which verifies the theoretical result (16):

$$
p^{*}\left(t, x^{*}(t)\right)=\frac{\beta x^{*}(t)}{-2 \alpha}+\frac{b-\alpha c}{-2 \alpha}=0.05 x^{*}(t)+40 .
$$

From Figure 3, it can be observed that the optimal replenishment cycle is about 1.50 and the optimal inventory level is 22 nearly with the optimal selling price 41 almost.

Next, one sample path of stochastic process I defined by (1) with the initial inventory level $I(0)=30.0$ and the length of replenishment cycle $T=1.5$ is simulated according to the discrete the control variable computed by the above numerical method.

From Figure 5, we can see that under the optimal dynamic pricing, the inventory level $I(t)$ decreases with the time 

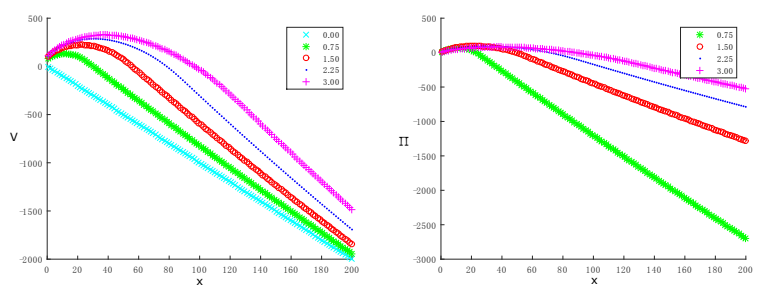

Fig. 3. $V(0, x ; T)$ and $\Pi(T, x)$ about the different values of $T$.
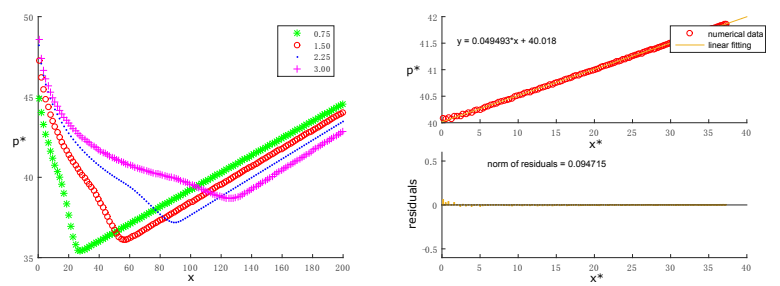

Fig. 4. $p^{*}(0, x)$ about the different values of $T$ and $p^{*}\left(t, x^{*}(t)\right)$.

and is zero before the next cycle. The optimal selling price increases with time when $I(t)>0$ and is equal to $\bar{p}$ when the stock is sold out. The function of the evolution curve of the net profit with the time shown in Figure 6 is equal to

$\int_{0}^{t} p^{*}(s, I(s)) d D\left(s, p^{*}(s, I(s)), I(s)\right)-c x-\int_{0}^{t} h I(s) d s$

if $I(t)>0$ and $t<T$, otherwise it is equal to

$$
\begin{aligned}
& \int_{0}^{\tau} p^{*}(s, I(s)) d D\left(s, p^{*}(s, I(s)), I(s)\right)+s_{v} I(\tau)-c x \\
& -\int_{0}^{\tau} h I(s) d s+\int_{\tau}^{t}\left[p^{*}(s, I(s))-c\right] e^{-\gamma(t-s)} d D(s)
\end{aligned}
$$

where

$$
\tau=\inf \{s>0:(s, I(s)) \notin(0, T) \times(0, U)\},
$$

and $I(s)$ is the inventory level for the stochastic inventory system (1) with the optimal selling price $p^{*}(s, I(s))$ and $I(0)=30.0$.
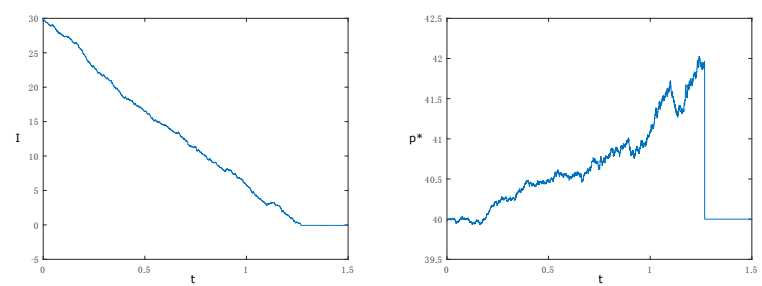

Fig. 5. The evolution curves of the inventory level and the optimal selling price with the time.

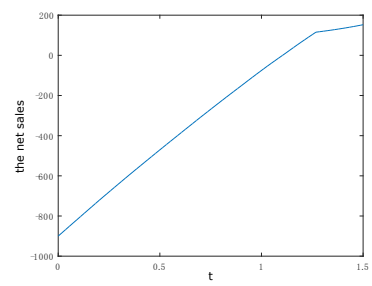

Fig. 6. The evolution curve of the net profit with the time.

\section{Sensitivity Analysis}

In this section, we will discuss the influences of changes in the major parameters of the system on the optimal length of replenishment cycle $T^{*}$, the optimal inventory level $x^{*}\left(0 ; T^{*}\right)$, the optimal selling price $p^{*}\left(0, x^{*}\left(0 ; T^{*}\right)\right)$, and the optimal total profit per unit time $\Pi\left(T^{*}\right)$ according to (4) and (6). The model parameters are given as follows:

$$
\begin{aligned}
& \alpha=-2.0, b=100.0, \beta=0.20, C=80.0, c=30.0, \\
& h=5.0, s_{v}=20, \sigma_{1}=0.01, \sigma_{2}=0.01, \theta=0.05, \\
& \gamma=2.0, U=200, N=K=5000 .
\end{aligned}
$$

Example 12 The optimal inventory level, the optimal unit selling price, and the optimal total profit per unit time are obtained with respect to the optimal replenishment cycle about the different values of $\alpha=-2.4,-2.0,-1.6,-1.2$ as shown in Figures 7, 8, and Table 1. Based on the computational results, the following inferences can be made from the managerial point of view:

- It can be observed that for the fixed replenishment cycle length $T, \Pi(T), x^{*}(0 ; T)$, and $p^{*}\left(0, x^{*}(0 ; T)\right)$ increase with an increase in the marginal demand rate of selling price $\alpha$, which indicates that if the selling price impact on demand rate is less, the retailer will raise selling price to get higher profit.

- When $\alpha=-2.4$, the retailer should keep less stock, bring the selling price down, and reduce the replenishment frequency because of small actual market demand rate $b+\alpha c=28$

- When $\alpha=-1.2$, the actual market demand rate $b+$ $\alpha c=64$ is large, so the retailer should keep more stocks and raise the selling price to maximize the profit. Since $U$ is large enough, there is no need to replenish frequently.

Example 13 The optimal inventory level, the optimal unit selling price, and the optimal total profit per unit time are obtained with respect to the optimal replenishment cycle about the different values of $\beta=0.30,0.25,0.20,0.15$ as shown in Figures 9, 10, and Table 2. Based on the computational results, the following conclusions can be made:

- For a fixed replenishment cycle length $T$, $(T)$, 


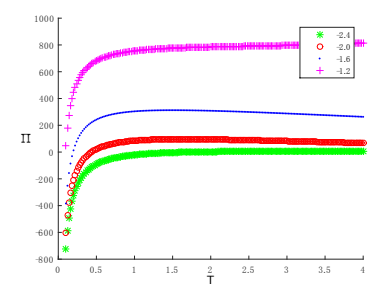

Fig. 7. $\Pi\left(T, x^{*}(0 ; T)\right)$ with respect to $T$ about the different values of $\alpha$.
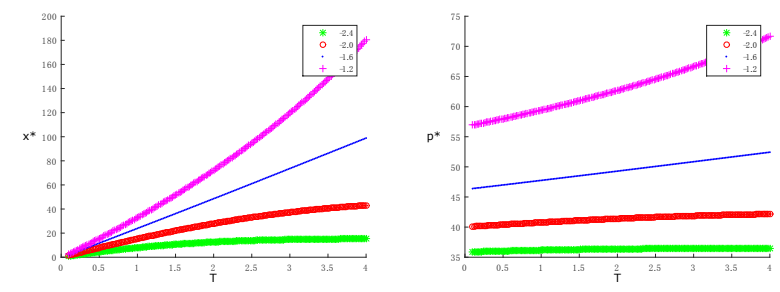

Fig. 8. $x^{*}(0 ; T)$ and $p^{*}\left(0, x^{*}(0 ; T)\right)$ with respect to $T$ about the different values of $\alpha$.

\begin{tabular}{c|cccc}
\hline$\alpha$ & $T^{*}$ & $x^{*}\left(0 ; T^{*}\right)$ & $p^{*}\left(0, T^{*}\right)$ & $\Pi\left(T^{*}\right)$ \\
\hline-2.4 & 2.9530 & 14.5964 & 36.4478 & 4.5003 \\
-2.0 & 1.6370 & 23.6941 & 41.1857 & 95.9880 \\
-1.6 & 1.4980 & 36.1410 & 48.5140 & 312.7481 \\
-1.2 & 4.0000 & 180.5549 & 71.7135 & 813.6761 \\
\hline
\end{tabular}

Table 1

The effects of $\alpha$ on $T^{*}, x^{*}\left(0 ; T^{*}\right), p^{*}\left(0, T^{*}\right)$, and $\Pi\left(T^{*}\right)$.

$x^{*}(0 ; T)$, and $p^{*}\left(0, x^{*}(0 ; T)\right)$ decrease with the decreasing in the marginal demand of inventory level $\beta$, which demonstrates that the larger the marginal demand rate of stock is, the higher the inventory level at the start of cycle is.

- When $\beta$ decreases, the optimal replenishment cycle length $T^{*}$ decreases while $\Pi\left(T^{*}\right), x^{*}\left(0 ; T^{*}\right)$, and $p^{*}\left(0, x^{*}\left(0 ; T^{*}\right)\right)$ decrease, which implies that the retailer should order more goods and improve selling price when $\beta$ is large.

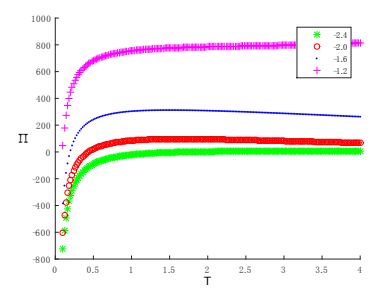

Fig. 9. $\Pi\left(T, x^{*}(0 ; T)\right)$ with respect to $T$ about the different values of $\beta$.

Example 14 The optimal inventory level, the optimal unit selling price, and the total profit per unit time are obtained with respect to the optimal replenishment cycle about the different values of $\gamma=50,10,2,0.4$ as shown in Figure 11, 12 and Table 3. Based on the computational
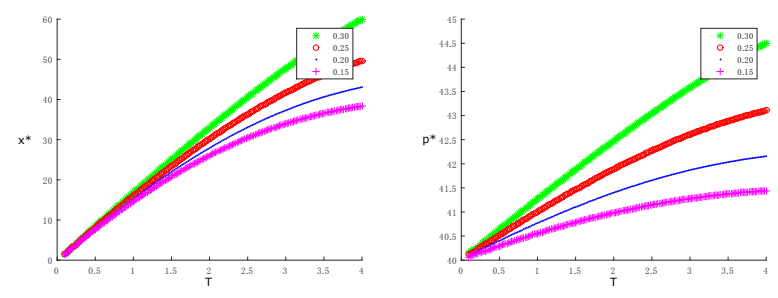

Fig. 10. $x^{*}(0 ; T)$ and $p^{*}\left(0, x^{*}(0 ; T)\right)$ with respect to $T$ about the different values of $\beta$.

\begin{tabular}{c|cccc}
\hline$\beta$ & $T^{*}$ & $x^{*}\left(0 ; T^{*}\right)$ & $p^{*}\left(0, T^{*}\right)$ & $\Pi\left(T^{*}\right)$ \\
\hline 0.30 & 1.7910 & 29.6926 & 42.2291 & 105.7896 \\
0.25 & 1.6980 & 26.1435 & 41.6388 & 100.4567 \\
0.20 & 1.6370 & 23.6941 & 41.1875 & 95.9880 \\
0.15 & 1.5910 & 21.7946 & 40.8212 & 92.1314 \\
\hline
\end{tabular}

Table 2

The effects of $\beta$ on $T^{*}, x^{*}\left(0 ; T^{*}\right), p^{*}\left(0, T^{*}\right)$, and $\Pi\left(T^{*}\right)$.

results, the following conclusions can be made:

- For a fixed replenishment cycle length $T, x^{*}(0 ; T)$ and $p^{*}\left(0, x^{*}(0 ; T)\right)$ decrease whereas $\Pi(T)$ increases with the decreasing in the punishment coefficient of shortage $\gamma$, which represents that the larger the shortage cost is, the higher the inventory level at the start of cycle is.

- When $\gamma$ decreases, the optimal replenishment cycle length $T^{*}$ increases while $\Pi\left(T^{*}\right)$ increases whereas $x^{*}\left(0 ; T^{*}\right)$ decreases, which demonstrates that the retailers should order fewer goods and reduce the selling price when the shortage cost is small.

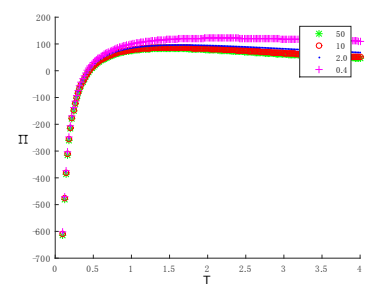

Fig. 11. $\Pi\left(T, x^{*}(0 ; T)\right)$ with respect to $T$ about the different values of $\gamma$.
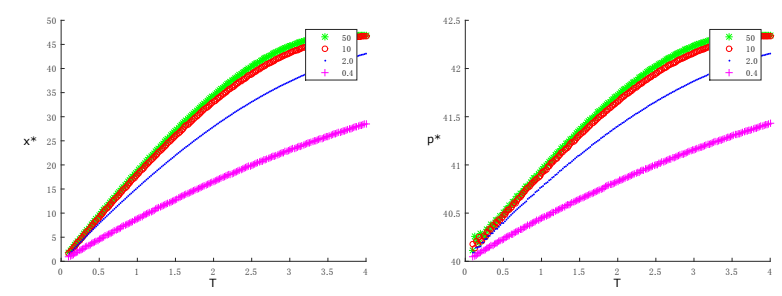

Fig. $12 . x^{*}(0 ; T)$ and $p^{*}\left(0, x^{*}(0 ; T)\right)$ with respect to $T$ about the different values of $\gamma$.

Example 15 The optimal inventory level, the optimal unit selling price, and the total profit per unit time are obtained with respect to the optimal replenishment cycle 


\begin{tabular}{c|cccc}
\hline$\gamma$ & $T^{*}$ & $x^{*}\left(0 ; T^{*}\right)$ & $p^{*}\left(0, T^{*}\right)$ & $\Pi\left(T^{*}\right)$ \\
\hline 50 & 1.4730 & 26.5934 & 41.3392 & 83.3897 \\
10 & 1.4940 & 25.9435 & 41.3059 & 86.1470 \\
2 & 1.6370 & 23.6941 & 41.1875 & 95.9880 \\
0.4 & 2.1690 & 17.6956 & 40.8906 & 121.6588 \\
\hline Table 3 & & & &
\end{tabular}

The effects of $\gamma$ on $T^{*}, x^{*}\left(0 ; T^{*}\right), p^{*}\left(0, T^{*}\right)$, and $\Pi\left(T^{*}\right)$.

about the different values of $\theta=0.13,0.09,0.05,0.01$ as shown in Figures 13, 14, and Table 4. Based on the computational results, the following features are observed:

- For a fixed replenishment cycle length $T$, when the deterioration rate $\theta$ decreases, $\Pi(T), x^{*}(0 ; T)$, and $p^{*}\left(0, x^{*}(0 ; T)\right)$ increase. For the greater deterioration rate, the optimal selling price is lower, which means that for perishable products, the retailers should reduce the selling price to increase sales instead of raising the price to cover the deterioration cost.

- It can be found that $T^{*}$ and $\Pi\left(T^{*}\right)$ increase with the decreasing in the deterioration rate $\theta$. Also, it is noted that the optimal replenishment cycle length and the optimal total profit per unit time are highly sensitive to the change in the deterioration rate.

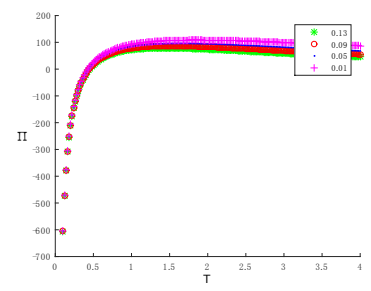

Fig. 13. $\Pi\left(T, x^{*}(0 ; T)\right)$ with respect to $T$ about the different values of $\theta$.
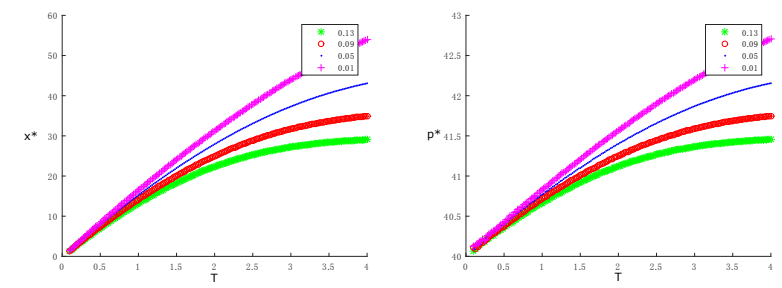

Fig. 14. $x^{*}(0 ; T)$ and $p^{*}\left(0, x^{*}(0 ; T)\right)$ with respect to $T$ about the different values of $\theta$.

\begin{tabular}{c|cccc}
\hline$\theta$ & $T^{*}$ & $x^{*}\left(0 ; T^{*}\right)$ & $p^{*}\left(0, T^{*}\right)$ & $\Pi\left(T^{*}\right)$ \\
\hline 0.13 & 1.2250 & 21.2947 & 41.0753 & 54.7748 \\
0.09 & 1.3300 & 23.6941 & 41.1902 & 67.4064 \\
0.05 & 1.4810 & 26.9933 & 41.3573 & 81.7832 \\
0.01 & 1.7220 & 32.1420 & 41.6125 & 98.6899 \\
\hline
\end{tabular}

The effects of $\theta$ on $T^{*}, x^{*}\left(0 ; T^{*}\right), p^{*}\left(0, T^{*}\right)$, and $\Pi\left(T^{*}\right)$.
Remark 16 Using the data in Tables 1, 2, 3 and 4, it is easy to verify that $\Pi^{*}\left(T^{*}\right)$ is equal to

$$
\frac{1}{-4 \alpha}\left[b+\alpha c+\beta x^{*}\left(0 ; T^{*}\right)\right]^{2}-(c \theta+h) x^{*}\left(0 ; T^{*}\right)
$$

approximately, which is consistent with the theoretic results given in (17).

\section{Conclusions}

In this paper, the dynamic pricing and the periodic replenishment strategy for a stochastic inventory system with deteriorating items are considered. First of all, we formulate the problem into a stochastic optimal control model, which is transformed into an HJB equation based on the dynamic programming principle. Then, some useful theoretical results are derived to characterize the optimal solutions, and the optimal replenishment cycle length with the optimal inventory level at start of cycle and the optimal pricing strategies have be given. In addition, the finite difference scheme with the semi-smooth Newton method is proposed to solve the HJB equation numerically. The numerical simulations are presented to illustrate the theoretical results. The sensitivity analysis of the optimal solutions with respect to the major parameters is carried out, and some managerial insights are proposed.

\section{Acknowledgements}

The authors would like to thank the editor and the anonymous referees for their constructive and insightful comments for improving the quality of this work. Furthermore, we thank Professor Suresh P Sethi for his comments and suggestions to refine this article.

Support for this work is provided by the financial support from the National Science Foundation of China (NSFC 91330202, 11371026, 11201501, 11171251, 71302115), the National Basic Research Program (2012CB955804), the Major Research Plan of the National Natural Science Foundation of China (91430108), the Scientific Research Development Foundation of Tianjin University of Finance and Economics (2014Q140118), the Major Program of Tianjin University of Finance and Economics (ZD1302).

\section{References}

Abad, P. (2000). Optimal lot size for a perishable good under conditions of finite production and partial backordering and lost sale. Computers 85 Industrial Engineering, 38(4):457-465.

Baker, R. and Urban, T. L. (1988). A deterministic inventory system with an inventory-level-dependent 
demand rate. Journal of the Operational Research Society, 39(9):823-831.

Bakker, M., Riezebos, J., and Teunter, R. H. (2012). Review of inventory systems with deterioration since 2001. European Journal of Operational Research, 221(2):275-284.

Banerjee, A. (2005). Concurrent pricing and lot sizing for make-to-order contract production. International Journal of Production Economics, 93:189-195.

Barles, G. and Jakobsen, E. R. (2007). Error bounds for monotone approximation schemes for parabolic Hamilton-Jacobi-Bellman equations. Mathematics of Computation, 76(260):1861-1893.

Barles, G. and Souganidis, P. E. (1991). Convergence of approximation schemes for fully nonlinear second order equations. Asymptotic Analysis, 4(3):271-283.

Chang, H.-J. and Dye, C.-Y. (1999). An EOQ model for deteriorating items with time varying demand and partial backlogging. Journal of the Operational Research Society, 50(11):1176-1182.

Chang, H.-J. and Dye, C.-Y. (2001). An inventory model for deteriorating items with partial backlogging and permissible delay in payments. International Journal of Systems Science, 32(3):345-352.

Chen, X. and Simchi-Levi, D. (2004). Coordinating, control and pricing strategies with random demand and fixed ordering cost: the finite horizon case. Operations Research, 52(6):887-896.

Chen, X. and Simchi-Levi, D. (2006). Coordinating inventory control and pricing strategies: the continuous review model. Operations Research Letters, 34(3):323332.

Covert, R. P. and Philip, G. C. (1973). An EOQ model for items with Weibull distribution deterioration. AIIE Transactions, 5(4):323-326.

Datta, T., Paul, K., and Pal, A. (1998). Demand promotion by upgradation under stock-dependent demand situation-a model. International Journal of Production Economics, 55(1):31-38.

Federgruen, A. and Heching, A. (1999). Combined pricing and inventory control under uncertainty. Operations Research, 47(3):454-475.

Fleming, W. H. and Soner, H. M. (2006). Controlled Markov Processes and Viscosity Solutions, volume 25. Springer.

Ghare, P. and Schrader, G. (1963). A model for exponentially decaying inventory. Journal of Industrial Engineering, 14(5):238-243.

Giri, B., Pal, S., Goswami, A., and Chaudhuri, K. (1996). An inventory model for deteriorating items with stockdependent demand rate. European Journal of Operational Research, 95(3):604-610.

Goyal, S. and Giri, B. C. (2001). Recent trends in modeling of deteriorating inventory. European Journal of Operational Research, 134(1):1-16.

Gupta, R. and Vrat, P. (1986). Inventory model with multi-items under constraint systems for stock dependent consumption rate. Operations Research, 24(1):41-42.
Hollter, R. and Mak, K. (1983). Inventory replenishment policies for deteriorating items in a declining market. The International Journal of Production Research, 21(6):813-836.

Khouja, M. J. (2000). Optimal ordering, discounting, and pricing in the single-period problem. International Journal of Production Economics, 65(2):201216.

Kushner, H. and Dupuis, P. G. (2013). Numerical Methods for Stochastic Control Problems in Continuous Time, volume 24. Springer Science \& Business Media.

Ladany, S. and Sternlieb, A. (1974). The interaction of economic ordering quantities and marketing policies. AIIE Transactions, 6(1):35-40.

Lau, A. H. L. and Lau, H.-S. (2003). Effects of a demandcurve's shape on the optimal solutions of a multiechelon inventory/pricing model. European Journal of Operational Research, 147(3):530-548.

Li, S., Zhang, J., and Tang, W. (2015). Joint dynamic pricing and inventory control policy for a stochastic inventory system with perishable products. International Journal of Production Research, 53(10):29372950.

Lilien, G. L. and Kotler, P. (1983). Marketing Decision Making: A Model-Building Approach. Harper \& Row New York, NY.

Maddah, B. and Bish, E. K. (2007). Joint pricing, assortment, and inventory decisions for a retailer's product line. Naval Research Logistics (NRL), 54(3):315-330.

Mandal, B. and Phaujdar, S. (1989). An inventory model for deteriorating items and stock-dependent consumption rate. Journal of the Operational Research Society, 40(5):483-488.

Øksendal, B. K. (2003). Stochastic Differential Equations. Springer.

Padmanabhan, G. and Vrat, P. (1995). EOQ models for perishable items under stock dependent selling rate. European Journal of Operational Research, 86(2):281292.

Pal, S., Goswami, A., and Chaudhuri, K. (1993). A deterministic inventory model for deteriorating items with stock-dependent demand rate. International Journal of Production Economics, 32(3):291-299.

Papachristos, S. and Skouri, K. (2000). An optimal replenishment policy for deteriorating items with time-varying demand and partial-exponential typebacklogging. Operations Research Letters, 27(4):175184.

Papachristos, S. and Skouri, K. (2003). An inventory model with deteriorating items, quantity discount, pricing and time-dependent partial backlogging. International Journal of Production Economics, 83(3):247-256.

Park, K. S. (1982). Inventory model with partial backorders. International Journal of Systems Science, 13(12):1313-1317.

Philip, G. C. (1974). A generalized EOQ model for items with Weibull distribution deterioration. AIIE Transactions, 6(2):159-162. 
Polatoglu, L. H. (1991). Optimal order quantity and pricing decisions in single-period inventory systems. International Journal of Production Economics, 23(1):175-185.

Ray, J. and Chaudhuri, K. (1997). An EOQ model with stock-dependent demand, shortage, inflation and time discounting. International Journal of Production Economics, 53(2):171-180.

Ray, J., Goswami, A., and Chaudhuri, K. (1998). On an inventory model with two levels of storage and stockdependent demand rate. International Journal of Systems Science, 29(3):249-254.

Rosenblatt, M. J. and Lee, H. L. (1985). Improving profitability with quantity discounts under fixed demand. IIE Transactions, 17(4):388-395.

Schary, P. B. and Becker, B. W. (1972). Distribution and final demand: the influence of availability. Review of Financial Economics, 8(1):17-26.

Sethi, S. P. and Thompson, G. L. (2000). Optimal Control TheoryApplications to Management Science and Economics. Springer.

Shah, Y. (1977). An order-level lot-size inventory model for deteriorating items. AIIE Transactions, 9(1):108112 .

Smears, I. (2014). Hamilton-Jacobi-Bellman equations analysis and numerical analysis. Technical report, University of Oxford.

Soni, H. N. (2013). Optimal replenishment policies for deteriorating items with stock sensitive demand under two-level trade credit and limited capacity. Applied Mathematical Modelling, 37(8):5887-5895.

Teng, J.-T., Krommyda, I.-P., Skouri, K., and Lou, K.R. (2011). A comprehensive extension of optimal ordering policy for stock-dependent demand under progressive payment scheme. European Journal of Operational Research, 215(1):97-104.

Urban, T. L. (1992). An inventory model with an inventory-level-dependent demand rate and relaxed terminal conditions. Journal of the Operational Research Society, 43(7):721-724.

Wang, S.-P. (2002). An inventory replenishment policy for deteriorating items with shortages and partial backlogging. Computers $\&$ Operations Research, 29(14):2043-2051.

Wee, H.-M. (1995). A deterministic lot-size inventory model for deteriorating items with shortages and a declining market. Computers $\& 5$ Operations Research, $22(3): 345-356$.

Weng, Z. K. (1995). Modeling quantity discounts under general price-sensitive demand functions: Optimal policies and relationships. European Journal of Operational Research, 86(2):300-314.

Whitin, T. M. (1955). Inventory control and price theory. Management Science, 2(1):61-68.

Wolfe, H. B. (1968). A model for control of style merchandise. Industrial Management Review, 9(2):69-82.

Yang, C.-T., Ouyang, L.-Y., Wu, K.-S., and Yen, H.-F. (2011). An optimal replenishment policy for deteriorating items with stock-dependent demand and re- laxed terminal conditions under limited storage space. Central European Journal of Operations Research, 19(1):139-153.

You, P.-S. and Hsieh, Y.-C. (2007). An EOQ model with stock and price sensitive demand. Mathematical and Computer Modelling, 45(7):933-942.

\section{A The Numerical Scheme}

In this Appendix, the finite difference scheme with the semi-smooth Newton method is proposed to solve the HJB equation (11) numerically, and the details are presented as follows.

The finite difference operators used for the KushmerDupuis Scheme proposed by Kushner and Dupuis (2013) are

$$
\begin{aligned}
\Delta_{t}^{+} v(t, x)= & \frac{1}{\Delta t}(v(t+\Delta t, x)-v(t, x)), \\
\Delta_{x}^{+} v(t, x)= & \frac{1}{\Delta x}(v(t, x+\Delta x)-v(t, x)), \\
\Delta_{x}^{-} v(t, x)= & \frac{1}{\Delta x}(v(t, x)-v(t, x-\Delta x)), \\
\Delta_{x x} v(t, x)= & \frac{1}{(\Delta x)^{2}}(v(t, x+\Delta x)+v(t, x-\Delta x) \\
& -2 v(t, x)) .
\end{aligned}
$$

First, let the set $\left\{t_{k}=k \Delta t\right\}_{k=0}^{K}$ be an equipartition of $[0, T]$ with interval length $\Delta t$ and the set $\left\{x_{i}=i \Delta x\right\}_{i=0}^{N+1}$ be an equipartition of $[0, U]$ with interval length $\Delta x$. Set

$$
\begin{aligned}
\mathcal{L}_{h}^{p} v\left(t_{k}, x_{i}\right)= & -\frac{1}{2}\left(\sigma_{1}^{2} x_{i}^{2}+\sigma_{2}^{2}\right) \Delta_{x x} v\left(t_{k}, x_{i}\right) \\
& -\left[\left(-\theta x_{i}-\left(b+\alpha p+\beta x_{i}\right)\right)^{+} \Delta_{x}^{+} v\left(t_{k}, x_{i}\right)\right. \\
& \left.-\left(-\theta x_{i}-\left(b+\alpha p+\beta x_{i}\right)\right)^{-} \Delta_{x}^{-} v\left(t_{k}, x_{i}\right)\right],
\end{aligned}
$$

where

$$
\begin{aligned}
& \left(b+\alpha p+\beta x_{i}\right)^{+}=\max \left\{0,\left(b+\alpha p+\beta x_{i}\right)\right\} \\
& \left(b+\alpha p+\beta x_{i}\right)^{-}=\max \left\{0,-\left(b+\alpha p+\beta x_{i}\right)\right\} .
\end{aligned}
$$

For (11), we get the discrete scheme: $\forall i=1, \cdots, N$ and $k=M-1, \cdots, 0$

$$
\begin{aligned}
\sup _{p \in \Lambda\left(x_{i}\right)}\{ & \frac{u_{h}\left(t_{k+1}, x_{i}\right)-u_{h}\left(t_{k}, x_{i}\right)}{\Delta t} \\
& \left.-\mathcal{L}_{h}^{p} u_{h}\left(t_{k}, x_{i}\right)+f\left(t_{k}, x_{i}, p\right)\right\}=0 .
\end{aligned}
$$

Equivalently, we get

$$
\begin{aligned}
\inf _{p \in \Lambda\left(x_{i}\right)}\{ & \frac{u_{h}\left(t_{k}, x_{i}\right)}{\Delta t}+\mathcal{L}_{h}^{p} u_{h}\left(t_{k}, x_{i}\right) \\
& \left.-\frac{u_{h}\left(t_{k+1}, x_{i}\right)}{\Delta t}-f\left(t_{k}, x_{i}, p\right)\right\}=0 .
\end{aligned}
$$


More specifically, for all $i=1,2, \cdots, N$ and $k=K-$ $1, \cdots, 0$, it holds that

$$
\begin{aligned}
\inf _{p \in \Lambda\left(x_{i}\right)}\{ & \left(1+\frac{1}{2}\left(\sigma_{1}^{2} x_{i}^{2}+\sigma_{2}^{2}\right) \frac{2 \Delta t}{(\Delta x)^{2}}\right. \\
& +\frac{\Delta t}{\Delta x}\left[\left(-\theta x_{i}-\left(b+\alpha p+\beta x_{i}\right)\right)^{+}\right. \\
& \left.\left.+\left(-\theta x_{i}-\left(b+\alpha p+\beta x_{i}\right)\right)^{-}\right]\right) u_{h}\left(t_{k}, x_{i}\right) \\
& +\left(-\frac{1}{2}\left(\sigma_{1}^{2} x_{i}^{2}+\sigma_{2}^{2}\right) \frac{\Delta t}{(\Delta x)^{2}}\right. \\
& \left.-\frac{\Delta t}{\Delta x}\left(-\theta x_{i}-\left(b+\alpha p+\beta x_{i}\right)\right)^{+}\right) u_{h}\left(t_{k}, x_{i+1}\right) \\
& +\left(-\frac{1}{2}\left(\sigma_{1}^{2} x_{i}^{2}+\sigma_{2}^{2}\right) \frac{\Delta t}{(\Delta x)^{2}}\right. \\
& \left.-\frac{\Delta t}{\Delta x}\left(-\theta x_{i}-\left(b+\alpha p+\beta x_{i}\right)\right)^{-}\right) u_{h}\left(t_{k}, x_{i-1}\right) \\
& -\Delta t\left((p-c)\left(b+\alpha p+\beta x_{i}\right)\right. \\
& \left.\left.-c \theta x_{i}-h x_{i}\right)-u_{h}\left(t_{k+1}, x_{i}\right)\right\}=0
\end{aligned}
$$

with the final condition $u_{h}\left(t_{M}, x_{i}\right)=g\left(T, x_{i}\right)$ and the boundary condition $u_{h}\left(t, x_{0}\right)=g\left(t, x_{0}\right)$. Here the Neumann boundary condition $u_{h}\left(t, x_{N+1}\right)=u_{h}\left(t, x_{N}\right)$ should also be needed.

Then for each time step, we should solve the following nonlinear equations:

$$
\inf _{p \in \Lambda}\left[A^{p} u_{h}-d^{p}\right]=0
$$

where $A^{p}=\frac{1}{\Delta t} I+L^{p}$ and $I$ is the identity matrix, $L^{p}$ is the triple diagonal matrix obtained from the discrete scheme (A.2). The infimum is understood here in the component-wise sense: $\forall i=1,2 \cdots, N$,

$$
\left(\inf _{p \in \Lambda}\left[A^{p} u_{h}-d^{p}\right]\right)_{i}=\inf _{p \in \Lambda\left(x_{i}\right)}\left(A^{p} u_{h}-d^{p}\right)_{i}
$$

The semi-smooth Newton method is proposed to solve the nonlinear equations (A.3). First, let the initial guess $y_{1} \in \mathbb{R}^{N}$. Then, for the given $y_{m}, m \in \mathbb{N}^{+}$, let $y_{m+1}$ be the unique solution of

$$
G\left(y_{m}\right) y_{m+1}=d\left(y_{m}\right)
$$

where for all $i, j \in\{1, \cdots, N\},\left(G\left(y_{m}\right)\right)_{i j}=\left(A^{p_{i}\left(y_{m}\right)}\right)_{i j}$, $\left(d\left(y_{m}\right)\right)_{i}=\left(d^{p_{i}\left(y_{m}\right)}\right)_{i}, p_{i}\left(y_{m}\right) \in \Lambda_{i}\left(y_{m}\right)$, and

$\Lambda_{i}(y)=\left\{p \in \Lambda\left(x_{i}\right) \mid\left(A^{p} y-d^{p}\right)_{i} \geq\left(A^{q} y-d^{q}\right)_{i}, \forall q \in \Lambda\right\}$.

If $\left|y_{m+1}-y_{m}\right|<\epsilon$, stop. Otherwise, set $m=m+1$ and return back. Algorithm 1 describes the process of comput- ing the discrete HJB equations (A.2) with the time iteration based on the semi-smooth Newton method. If the algorithm is convergent, $u_{h}\left(t_{k}, x_{i}\right)=u_{i}^{k}$ and $p_{h}\left(t_{k}, x_{i}\right)=$ $p_{i}^{k}$, which are the approximate value function and the approximate control variable, respectively.

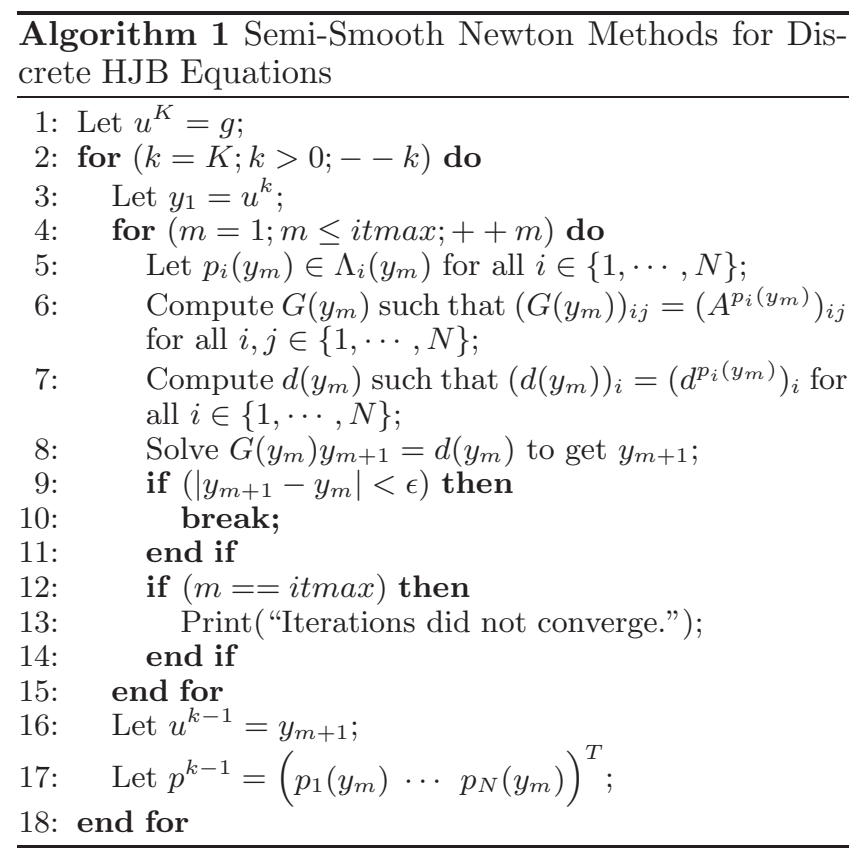

